\title{
Glucocorticoid insensitive asthma: a one year clinical follow up pilot study
} Pascal Demoly, Dany Jaffuel, Marc Mathieu, Hocine Sahla, Philippe Godard,
François-Bernard Michel, Jean Bousquet
Maladies

Respiratoires, INSERM U454, Hôpital Arnaud de Villeneuve, CHU de Montpellier, 34295

Montpellier Cedex 5,

France

P Demoly

D Jaffuel

M Mathieu

H Sahla

P Godard

F-B Michel

J Bousquet

Correspondence to: Dr P Demoly.

Received 22 April 1998 Returned to author 10 June 1998

Revised manuscript received

3 August 1998

Accepted for publication

20 August 1998

\begin{abstract}
Background-Glucocorticoid resistant or insensitive asthmatic subjects are usually defined as patients whose baseline prebronchodilation forced expiratory volume in one second $\left(\mathrm{FEV}_{1}\right)$ of less than $70-80 \%$ predicted improves significantly in response to $\beta_{2}$ agonists but by less than $15 \%$ following 1-2 weeks of $40 \mathrm{mg}$ prednisolone daily. Since there is little long term clinical information on these patients, a one year prospective study was performed to assess whether glucocorticoid sensitivity may vary over time.
\end{abstract}

Methods-Nineteen severe asthmatic subjects were studied and received $40 \mathrm{mg}$ prednisolone daily for seven days. Prednisolone was given for a further seven days in glucocorticoid insensitive asthmatics and then stopped. Patients were followed up for one year and the glucocorticoid test was repeated on five patients in each group six months later.

Results-Eleven patients were classified as glucocorticoid insensitive and eight as glucocorticoid sensitive on day 7 . The demographic characteristics of the patients were similar in both groups. Four glucocorticoid insensitive patients became responsive after one further week of prednisolone treatment. Six months later, four of five glucocorticoid sensitive patients and three of five previously glucocorticoid insensitive patients were glucocorticoid sensitive.

Conclusions-Glucocorticoid sensitivity varies over time.

(Thorax 1998;53:1063-1065)

Keywords: glucocorticoid; asthma; resistance; sensitivity

Most patients with asthma improve during treatment with glucocorticoids. ${ }^{1}$ However, a few patients show little or no improvement in pulmonary function after a short course of oral steroids and are thus classified as glucocorticoid resistant (or insensitive). It has been proposed that a definition of glucocorticoid insensitive asthmatic subjects is a baseline morning pre-bronchodilator forced expiratory volume in one second $\left(\mathrm{FEV}_{1}\right)$ of less than $70-80 \%$ pre- dicted, improving significantly in response to $\beta_{2}$ agonists but by less than $15 \%$ (from baseline values) following $40 \mathrm{mg}$ prednisolone daily for 1-2 weeks. ${ }^{2}$ This subset of asthmatic patients is heterogeneous and there has been no long term follow up of them. ${ }^{2}$

We therefore studied prospectively 19 severe asthmatics with a pre-bronchodilator $\mathrm{FEV}_{1}$ of less than $80 \%$ predicted to assess whether glucocorticoid sensitivity varies over time.

\section{Methods}

Nineteen patients of mean (SD) age 47 (14) years fulfilled the American Thoracic Society definition of asthma and had improved their $\mathrm{FEV}_{1}$ by more than $12 \%$ after inhalation of $200 \mu \mathrm{g}$ salbutamol. They had severe asthma as defined by the AsthmExpert ${ }^{\circledR}$ system ${ }^{3}$ and were managed according to asthma guidelines. ${ }^{1}$ They received high doses of inhaled glucocorticoids $(2000 \mu \mathrm{g}$ beclomethasone or equivalent) and long acting $\beta_{2}$ agonists and four patients were taking oral glucocorticoids in a daily dose of $7.5-15 \mathrm{mg}$. Beta agonists were stopped more than 12 hours before measurement of $\mathrm{FEV}_{1}$. Compliance with treatment was controlled. Patients were not included if they had been admitted to hospital during the month preceding the study. The diagnosis of atopy, rhinitis, and sinusitis was based on a previous paper. ${ }^{4}$

Patients received oral prednisolone $40 \mathrm{mg}$ daily for seven days and were classified as glucocorticoid insensitive (or glucocorticoid sensitive) as defined above. ${ }^{2}$ Thereafter, glucocorticoid insensitive patients continued with oral prednisolone $40 \mathrm{mg}$ daily for seven more days and $\mathrm{FEV}_{1}$ was reassessed at day 14 . Oral prednisolone was then discontinued and the patients were followed up for one year with their previous treatment according to asthma guidelines. ${ }^{1}$ Six months later the oral glucocorticoid test was repeated in 10 patients. Quantitative results are given as mean (SD) values.

\section{Results}

Eleven patients (eight men) were classified as glucocorticoid insensitive $\left(\Delta \mathrm{FEV}_{1} 4.3(4.6) \%\right)$ at day 7 and eight patients (seven men) were classified as glucocorticoid sensitive $\left(\Delta \mathrm{FEV}_{1}\right.$ 44.2 (18.9)\%; fig 1A). At entry to the study these two groups of patients were no different 

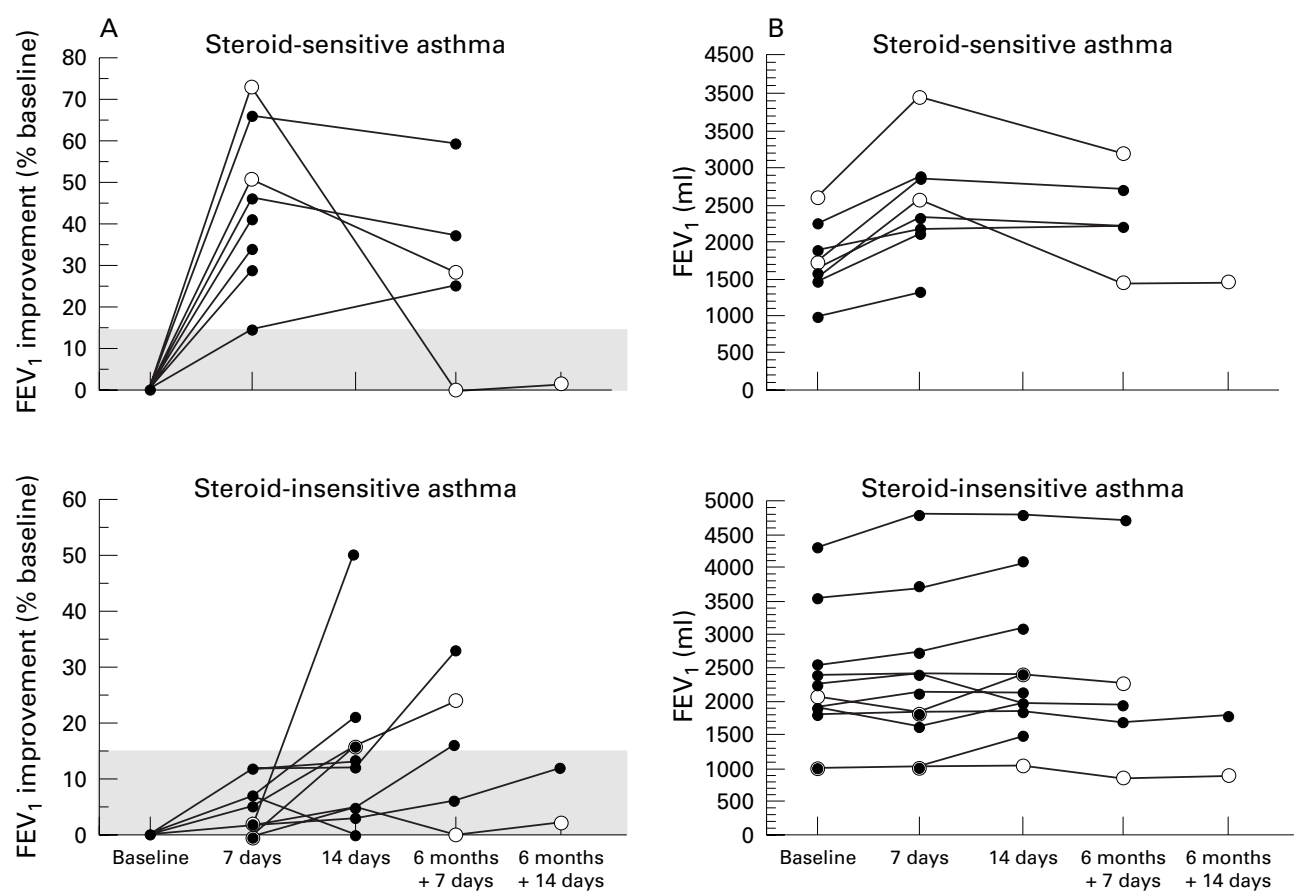

Figure 1 Change in FEV in patients with steroid sensitive and insensitive asthma: $(A)$ percentage change from baseline; (B) absolute values; $O=$ glucocorticoid dependent asthma; $\bullet=$ non-glucocorticoid dependent asthma.

in terms of asthma severity (AsthmExpert ${ }^{\circledR}$ score of 5), pre-bronchodilation $\mathrm{FEV}_{1}(53.1$ (17.6) $\%$ and 66.8 (11.4)\% predicted; fig 1B), improvement in $\mathrm{FEV}_{1}$ after $200 \mu \mathrm{g}$ salbutamol (13.5 (8.3)\% and 19.5 (16.1)\% from baseline). They did not differ in mean age (47 (16) and 48 (14) years), duration of asthma (18 (11) and 15 (9) years), presence of atopy (11/11 and 5/8 with seasonal exacerbations in $3 / 11$ and $1 / 5$ ), or rhinosinusitis (8/11 and 6/8). Two patients in both groups were glucocorticoid dependent.

After seven days of treatment with prednisolone most glucocorticoid insensitive asthmatics remained sensitive to salbutamol (21.5 (20.5)\% from baseline) compared with glucocorticoid sensitive patients $(4.9$ (6.5)\% from baseline) whose $\mathrm{FEV}_{1}$ had probably improved to their maximum.

By prolonging prednisolone treatment for one week four of 11 glucocorticoid insensitive patients became glucocorticoid sensitive. The oral glucocorticoid test was repeated six months later in five patients in each group and one of five previously glucocorticoid sensitive patients became glucocorticoid insensitive. Conversely, three of five previously glucocorticoid insensitive patients became glucocorticoid sensitive.

During the one year follow up, mild to moderate asthma exacerbations (1.9 (1.9) and 1.5 (1.3) episodes in glucocorticoid insensitive and sensitive patients, respectively) and severe exacerbations requiring admission to hospital (0.4 (0.7) and 0.6 (1.4) episodes, respectively) were similar in the two groups.

\section{Discussion}

Glucocorticoid resistance or insensitivity may vary over time and this is important since it has been suggested that inflammation may contribute to a lack of response to glucocorticoid, in particular after allergen challenge. ${ }^{5}$ Although no definition of glucocorticoid insensitivity is ideal, the pragmatic definition of an "improvement in $\mathrm{FEV}_{1}$ of less than $15 \%$ after an adequate dose (40 mg) of oral glucocorticoid such as prednisolone for an adequate duration of time (1-2 weeks)" has recently been proposed, whether or not the patients are already taking daily oral glucocorticoids. ${ }^{2}$ In our study we have shown (some authors have only suggested ${ }^{2}$ ) that two weeks of treatment with prednisolone may be more suitable than one week since four of 11 so called glucocorticoid insensitive asthmatic subjects after seven days of treatment with oral glucocorticoid were no longer glucocorticoid insensitive after 14 days of treatment.

Not only is the duration of treatment important but the dose could also be crucial and there are very few large scale data on both duration and dose-response relationships between glucocorticoid and lung function. Patients who are insensitive to $40 \mathrm{mg}$ glucocorticoid may respond to higher doses, although during acute asthma exacerbations higher doses have not shown greater efficacy. ${ }^{6}$ It is possible that other oral glucocorticoids may be more effective as there is some evidence that methylprednisone is distributed better into the lungs than prednisolone. ${ }^{78}$ In glucocorticoid dependent asthmatic subjects a comparison of these three oral glucocorticoids did not show any clinical differences in one study, ${ }^{9}$ although betamethasone was reported to produce a better improvement in $\mathrm{FEV}_{1}$ than prednisolone in another study. ${ }^{10}$

A practical definition of glucocorticoid insensitivity based on both $\mathrm{FEV}_{1}$ and symptom scores during a sufficiently long follow up period would be more useful for physicians. For research purposes the current clinical defi- 
nition, which may allow basic researchers to elucidate some of the mechanisms of action of glucocorticoids and asthma pathophysiology, possibly allowing the development of a routine laboratory test to predict glucocorticoid response and to help in the development of novel anti-asthma therapies, should take our results into account.

1 NIH. Guidelines for the diagnosis and management of asthma. National Institutes of Health, National Heart, Lung and Blood Institute, Publication Number 97-4051, 1997.

2 Lee T, Brattsand R, Leung D. Corticosteroid action and resistance in asthma. Conclusions. Am f Respir Crit Care Med 1996;154:S178-9.

3 Rédier H, Daures JP, Michel C, et al. Assessment of the severity of asthma by an Expert system. Description and
evaluation. Am F Respir Crit Care Med 1995;151:345-52.
4 Bousquet J, Chanez P, Lacoste JY, et al. Eosinophilic inflammation in asthma. N Engl f Med 1990;323:1033-9.

5 Nimmagadda SR, Szefler SJ, Spahn JD, et al. Allergen exposure decreases glucocorticoid receptor binding affinity and steroid responsiveness in atopic asthmatics. Am $\mathcal{F}$ Respir Crit Care Med 1997;155:87-93.

6 Marquette $\mathrm{CH}$, Stach B, Cardot E, et al. High-dose and low-dose systemic corticosteroids are equally efficient in acute severe asthma. Eur Respir f 1995; 8:22-7.

7 Braude AC, Rebuck AS. Prednisone and methylprednisolone deposition in the lung. Lancet 1983;ii:995-7.

8 Vichyanond P, Irvin CG, Larsen GL, et al. Penetration of corticosteroids into the lung: evidence for a difference between methylprednisolone and prednisolone. F Allergy Clin Immunol 1989;84:867-73.

9 Chanez P, Paradis L, Des Roches A, et al. Comparison of three different oral corticosteroids in steroid-dependent asthma patients. Allergy 1996;51:850-1.

10 Grandordy B, Belmatoug N, Morelle A, et al. Effect of betamethasone on airway obstruction and bronchial response to salbutamol in prednisolone resistant asthma. Thorax 1987;42:65-71. 